\title{
Editorial
}

\section{Don't Shun the Shunt: Surgical Portosystemic Shunts in the Era of TIPS and Liver Transplantation}

\author{
Her-HsinTsai, MD, FRCP, FECG* \\ Consultant Physician and Gastroenterologist, Hull and East Yorkshire NHS Hospital Trusts, Hull Royal Infirmary, Anlaby Rd, Hull, East Riding of Yorkshire HU3 \\ 2JZ, UK
}

\section{*Corresponding author}

Her-HsinTsai, MD, FRCP, FECG

Consultant Physician and Gastroenterologist, Hull and East Yorkshire NHS Hospital Trusts, Hull Royal Infirmary,Anlaby Rd, Hull, East Riding of Yorkshire HU3 2JZ, UK;Tel. +55 I I 942683834; E-mail: colleti@gmail.com

\section{Article information}

Received: August 19 $9^{\text {th }}, 2018$; Accepted: August $21^{\text {st }}, 2018$; Published: August $21^{\text {st }}, 2018$

\section{Cite this article}

Tsai H-H. Don't Shun the Shunt: Surgical portosystemic shunts in the era of TIPS and liver transplantation. Liver Res Open J. 20I8; 3(I): el. doi: I0. I7I40/LROJ-3-e004

$\mathrm{P}$ ort-systemic shunt surgery has been on the retreat in the past 20 -years with the advent of minimally invasive techniques like transjugular intrahepatic portosystemic shunts (TIPS) and wider use of liver transplantation as the definitive treatment of end-stage liver disease. There is also increasing awareness of the limitations of surgical portal decompression. In the clinical context of poor hepatic function, such as in Child's B and C patients, decompression often precipitates incapacitating hepatic encephalopathy and may actually increase mortality.

However, intervention radiology is not widely available in many countries. These intravascular procedures are expensive both in set-up costs and expended equipment. Procedures are technically demanding and TIPS may not be possible because of anatomical reasons or when the portal vein is thrombosed. Liver transplantation is not universally available either through lack of availability of grafts or surgical expertise. Hence portosystemic shunt surgery is not entirely devoid of a role in the treatment of portal hypertension and its sequele. In selected populations, it may be a necessary even life-saving procedure. In this issue of Liver Research - Open Journal (LROJ) Nazyrov et al documents 50-years of experience of portosystemic shunt surgery, comparing the two distinct surgical techniques. ${ }^{1}$ It is refreshing that the results of porto-systemic shunt operations are being reviewed by these authors in this issue of LROJ. In a large series of 925 patients, Nazyrov et al looked at the survival and symptomatic improvements of these operations. Although it is not a controlled trial, the large series gives it a degree of legitimacy, of and as prospects of a future controlled trial is extremely remote, it is the best data we are likely to have.

Port-systemic shunt surgery still has a role and place in liver therapeutics in the $21^{\text {st }}$ century albeit in a very selected rare occasions or when it is the only available treatment. This paper by Nazyrov is not without merit and reminder that these surgical procedures should not be too readily confined to the surgical dustbin.

\section{REFERENCES}

1. Nazyrov FG, Devyatov AV, Babadjanov AK, et al. Comparisons between portosystemic shunting modalities in patients with liver cirrhosis and portal hypertension. Liver Res Open J. 2016; 2(1): 1-8. doi: 10.17140/LROJ-2-109 